\title{
Rituximab biosimilars in hematologic malignancies: the need for a real-world approach
}

\author{
Pilar Nava-Parada*,1,2, Ahmed Shelbaya ${ }^{1,3}$ \& Chadi Nabhan ${ }^{4,5}$ \\ ${ }^{1}$ Pfizer Inc, New York, NY 10017, USA \\ ${ }^{2}$ Health Advocacy \& Medical Exploration Society (HAMES National, Inc), Lawrence Township, NJ 08648, USA \\ ${ }^{3}$ Mailman School of Public Health, New York, NY 10032, USA \\ ${ }^{4}$ Caris Life Sciences, Irving, TX 75039, USA \\ ${ }^{5}$ Department of Clinical Pharmacy \& Outcomes Sciences, University of South Carolina, Columbia, SC 29208, USA \\ *Author for correspondence: Tel.: +1 212733 3585; Pilar.Nava-Parada@pfizer.com
}

The introduction of rituximab biosimilars into healthcare systems can potentially help to control healthcare costs for the treatment of hematologic malignancies. However, there are currently several barriers to the uptake of biosimilars. This review discusses barriers to the adoption of rituximab biosimilars by stakeholders including patients and healthcare providers. We outline the importance of utilizing real-world evidence in providing additional clinical experience on rituximab biosimilars in hematologic malignancies to improve stakeholder confidence regarding their efficacy and safety. We conclude by offering recommendations for designing and conducting effective real-world studies. Such studies can provide evidence to help achieve lower-priced biologics and improved patient access to help sustain the treatment of hematologic malignancies with biologics, including rituximab biosimilars.

First draft submitted: 17 February 2020; Accepted for publication: 11 June 2020; Published online: 13 July 2020

Keywords: biosimilars $\bullet$ hematologic malignancies $\bullet$ real-world evidence $\bullet$ rituximab

In the USA, healthcare expenditure for cancer treatment is increasing, partly due to the cost of biologic drugs, which creates a challenge for the future sustainability of affordable cancer care [1]. The increase in cancer incidence due to a rise in life expectancy and improved survival rates has extended the length of time that patients receive treatment and contributed to the escalation in cancer healthcare costs $[2,3]$. Rituximab (MabThera ${ }^{\circledR}$; Rituxan ${ }^{\circledR}$ ) is a chimeric monoclonal antibody that targets the B-cell-specific antigen CD20, and this biologic drug has transformed standard therapies for the majority of lymphoid malignancies [4]. Rituximab is approved for the treatment of several conditions, including - but not limited to - follicular lymphoma (FL), diffuse large B-cell lymphoma, and chronic lymphocytic leukemia $[5,6]$. However, patient access to rituximab can be restricted, particularly in countries with limited financial resources [7].

As patent portfolios for biologics near end of term, the availability of biosimilar versions of these drugs may mitigate the total cost of care by potentially providing more affordable treatment options, thereby increasing patient access to these important therapies $[1,8]$. Biosimilars are biologic drugs that are developed to be highly similar in structure and function to licensed (i.e., reference or originator) products, with no clinically meaningful differences in efficacy, safety and purity [9,10]. The Biologics Price Competition and Innovation Act of 2009 (enacted as part of the Affordable Care Act) provides an abbreviated approval pathway for biosimilars [9,11]. As such, the introduction of rituximab biosimilars into healthcare systems can potentially help to control the treatment costs for hematologic malignancies [12].

The availability of rituximab biosimilars, however, does not automatically guarantee their adoption in routine clinical practice. Despite the availability of a filgrastim biosimilar, its uptake in the USA has been less than anticipated and has lagged behind other countries where granulocyte-colony stimulating factor biosimilars for use in cancer supportive care are available [13]. In order to realize the potential savings for US healthcare systems, several barriers to the uptake of rituximab biosimilars need to be overcome. These barriers include the perceptions of stakeholders 
(including patients and healthcare providers), financial disincentives related to reimbursement, and regulatory policies (such as the interchangeability of reference products and biosimilars) $[8,11,14]$. Real-world evidence (RWE) can provide additional information to supplement the clinical data required by regulatory agencies as part of the abbreviated approval of biosimilars, to help overcome some of these barriers. The aim of this review is to discuss the current barriers to the uptake of biosimilars, the utility of RWE in providing additional clinical experience of the use of rituximab biosimilars for the treatment of hematologic malignancies, and recommendations for conducting effective real-world studies.

\section{Regulatory guidance \& rituximab biosimilars}

To gain regulatory approval, biosimilars must be sufficiently similar to the corresponding reference product such that they are not expected to show any clinically meaningful differences in safety, efficacy and purity demonstrated through a robust regulatory pathway. Similarity of a proposed biosimilar to its reference product is established using a 'totality-of-the-evidence' approach, comprising data from comparative analytical, preclinical, pharmacokinetic and clinical studies $[10,15]$. These confirmatory clinical studies are conducted to establish similarity to the reference product in terms of quality, efficacy and safety [16]. Biosimilars have the same mechanism of action as their corresponding reference product $[9,10]$. As such, with appropriate scientific justification, regulatory guidance permits the approval of a biosimilar in all eligible indications held by the reference product, without a comparative trial in each indication. This is known as extrapolation across indications $[9,10,17,18]$.

Many countries have now established regulatory pathways for the approval of biosimilars [9,10,18-22]. Rituximab biosimilars have been approved in the USA and the European Union through these pathways, using collective evidence from analytical, nonclinical and clinical studies. The comparative clinical studies were conducted in patients with either rheumatoid arthritis or FL, as these populations are adequately sensitive to detect meaningful differences in efficacy or safety between the biosimilar and reference rituximab (Table 1) [23-40]. There are also several rituximab biosimilars currently under development [41-44].

\section{Real-world studies}

The US FDA defines real-world data as "data relating to patient health status and/or the delivery of healthcare routinely collected from a variety of sources" [45]. These sources go beyond the traditional clinical trial setting and include electronic patient health records, claims data, product and disease registries, patient-reported outcomes (PROs) and other emerging data sources, such as social media and industry collaborations (Table 2) [46,47]. RWE is the "clinical evidence on the use and potential benefits or risks of a medical product derived from analysis of real-world data" [45]. Real-world studies can provide insights into different aspects of treatment and patient outcomes to enhance the evidence generated from conventional clinical trials in selected patient populations [48,49]. For example, data from electronic patient records were used to evaluate changes in practice efficiency by comparing subcutaneous and intravenous administration of rituximab [50]. RWE has also been used to inform early treatment milestones, understand treatment patterns, and provide patient perspectives regarding disease management for chronic myeloid leukemia [49].

RWE can be used to gain a more accurate insight into patient outcomes, for example, disease progression and long-term survival can be studied over longer time periods than those used in clinical trials [48]. By providing additional clinical experience of rituximab biosimilars, RWE supplements the clinical data required by regulatory agencies for the approval of biosimilars, and thereby potentially alleviate some of the current barriers to their uptake (Table 3) [8]. In addition, the evidence that is generated can be systematically analyzed to identify possible ways to improve disease management. However, real-world studies also have limitations, including internal validity, confounding factors, lack of standardization in assessing response and progression, variable data quality and increased risk of bias [47,51]. Furthermore, different sources of real-world data have their own strengths and limitations [47]. Therefore, translating real-world data into robust, clinically relevant evidence can be a challenge.

\section{Relevance of RWE to healthcare stakeholders}

Currently, real-world data are accumulated from disease registries mandated by regulatory authorities as part of the pharmacovigilance requirements for the approval of a biosimilar [52,53]. Data accumulated through pharmacovigilance could be used to inform physicians on the utilization of rituximab biosimilars in clinical practice, and to help inform discussions about treatment decisions between physicians and patients [54]. The availability of RWE on the use of biosimilars may also increase understanding among physicians and prescribers that comparative clinical 
Table 1. Rituximab biosimilars approved in the USA and the European Union for the treatment of hematological

malignancies ${ }^{\dagger}$

\begin{tabular}{|c|c|c|c|c|}
\hline Product & Key clinical studies & $\begin{array}{l}\text { Approved hematological } \\
\text { indications } \ddagger\end{array}$ & $\begin{array}{l}\text { Regulatory authority } \\
\text { (approval date) }\end{array}$ & Ref. \\
\hline $\begin{array}{l}\text { CT-P10 } \\
\text { (Truxima }{ }^{\circledR} \text { [rituximab-abbs], } \\
\text { Ritemvia }^{\circledR} \text {, Blitzima }{ }^{\circledR} ; \text { Celltrion) }\end{array}$ & $\begin{array}{l}\text { Pharmacokinetics trial }(n=154) \text { and extension study }(n=83) \text {; } \\
\text { randomized, double-blind study in patients with RA }(n=372) \text { : } \\
\text { - Similar PK and immunogenicity between CT-P10 and } \\
\text { reference rituximab } \\
\text { Randomized, double-blind studies in patients with previously } \\
\text { untreated advanced FL }(n=140) \text { and patients with LTB-FL } \\
(\mathrm{n}=258) \\
\text { - Similar PK, PD, efficacy, safety and immunogenicity } \\
\text { between CT-P10 and reference rituximab } \\
\text { - Similar PK, safety and efficacy between CT-P10 and } \\
\text { reference rituximab }\end{array}$ & $\mathrm{NHL} ; \mathrm{CLL} \mathbb{I}$ & $\begin{array}{l}\text { EMA (Feb 2017/Jul 2017); } \\
\text { US FDA (Nov 2018) }\end{array}$ & [23-31] \\
\hline $\begin{array}{l}\text { GP2013 } \\
\text { (Rixathon }{ }^{\circledR} / \text { Riximyo }^{\circledR} \S \text {; Sandoz) }\end{array}$ & $\begin{array}{l}\text { Randomized, double-blind efficacy and safety study in patients } \\
\text { with RA }(n=173) \text { : } \\
\text { - Similar PK, PD, safety, efficacy and immunogenicity } \\
\text { between GP2013 and reference rituximab } \\
\text { Randomized, double-blind study in patients with previously } \\
\text { untreated advanced FL }(n=629) \\
\text { - Similar efficacy and safety between GP2013 and reference } \\
\text { rituximab }\end{array}$ & $\mathrm{NHL} ; \mathrm{CLL}^{\S}$ & EMA (Jun 2017) & [32-35] \\
\hline $\begin{array}{l}\text { PF-05280586 (Ruxience }{ }^{T M}, \\
\text { rituximab-pvvr; Pfizer) }\end{array}$ & $\begin{array}{l}\text { Pharmacokinetics trial }(n=220) \text { and extension study }(n=185) \text { in } \\
\text { patients with active RA: } \\
\text { - Similar PK, PD, safety and immunogenicity demonstrated } \\
\text { between PF- } 05280586 \text { and reference rituximab } \\
\text { Randomized, double-blind efficacy and safety study in patients } \\
\text { with untreated CD20-positive LTB-FL }(n=394) \\
\text { - Similar efficacy, safety, immunogenicity, PK and PD between } \\
\text { PF-05280586 and reference rituximab }\end{array}$ & $\mathrm{NHL} ; \mathrm{CLL}$ & $\begin{array}{l}\text { US FDA (Jul 2019) } \\
\text { EMA (Apr 2020) }\end{array}$ & [36-40] \\
\hline \multicolumn{5}{|c|}{$\begin{array}{l}\text { †As of April } 2020 . \\
\text { ¥Some rituximab biosimilars are also approved to treat conditions including granulomatosis with polyangiitis, microscopic polyangiitis, pemphigus vulgaris and RA. } \\
\text { ICLL is not an approved indication for Ritemvia or rituximab-abbs. } \\
\S_{\text {Approved in the European Union as Riximyo under a duplicate marketing authorization for the treatment of NHL. }} \\
\text { \#Clinical program was developed in consultation with the US FDA and EMA to support the global development of the product. } \\
\text { CLL: Chronic lymphocytic leukemia; FL: Follicular lymphoma; LTB-FL: Low tumor-burden FL; NHL: Non-Hodgkin lymphoma; PD: Pharmacodynamic; PK: Pharmacokinetic; RA: Rheumatoid } \\
\text { arthritis. }\end{array}$} \\
\hline
\end{tabular}

\section{Table 2. Sources of real-world data.}

\begin{tabular}{|ll}
\hline Setting & Examples \\
\hline Research studies & $\begin{array}{l}\text { Observational studies } \\
\text { Post-approval safety studies }\end{array}$ \\
\hline Administrative claims databases & $\begin{array}{l}\text { Electronic patient health records } \\
\text { Patient medical charts } \\
\text { Patient registries (disease and product based) }\end{array}$ \\
\hline Pharmacy & Patient medical claims \\
\hline Patient & Prescription records \\
\hline Emerging data sources & Patient-reported outcomes \\
& Patient-powered research networks \\
Information from wearables and fitness trackers
\end{tabular}

studies of proposed biosimilars and the corresponding reference product are well-designed, and that data from these studies, which are required for regulatory approval, are reliable. In turn, this may improve the uptake of biosimilars.

In contrast to randomized clinical trials conducted in a selected patient population, patient populations in realworld settings are heterogeneous. RWE can therefore demonstrate the efficacy and safety of biosimilars in patient populations for whom clinical trial data are not available, such as children, the elderly, and those with concurrent medical conditions $[13,14,48,55]$. This aspect is of particular relevance in oncology as more than $95 \%$ of patients with cancer are treated outside of clinical trials [56]. In Europe, for example, real-world data from the Global Oncology Monitor (Ipsos Healthcare) have been used to evaluate prescription patterns for rituximab biosimilars [57]. This 
Table 3. Barriers to the uptake of biosimilars in the USA

\begin{tabular}{|lll|}
\hline Barrier & Issue & Role of real-world evidence \\
$\begin{array}{l}\text { Perception of stakeholders } \\
\text { (including physicians and } \\
\text { patients) }\end{array}$ & $\begin{array}{l}\text { Patients may be reluctant to switch from reference products to } \\
\text { biosimilars } \\
\text { Physicians lack confidence in prescribing biosimilars }\end{array}$ & $\begin{array}{l}\text { To inform educational programs for physicians and patients on the } \\
\text { efficacy and safety of rituximab biosimilars in more diverse patient } \\
\text { populations }\end{array}$ \\
\hline $\begin{array}{l}\text { Pricing and } \\
\text { reimbursement }\end{array}$ & $\begin{array}{l}\text { Healthcare providers may not be able to adopt biosimilars if payers } \\
\text { prefer the reference product in reimbursement models }\end{array}$ & $\begin{array}{l}\text { To demonstrate the market value of rituximab biosimilars (e.g., by } \\
\text { lowering treatment cost and improving patient access) to enable } \\
\text { payers to make decisions on reimbursement }\end{array}$ \\
\hline Regulatory policies & $\begin{array}{l}\text { Prescribers are unsure whether clinical data on the interchangeability } \\
\text { of reference products and biosimilars are reliable or whether } \\
\text { extrapolation of data across indications is permitted }\end{array}$ & $\begin{array}{l}\text { To provide data on the efficacy and safety of biosimilars in } \\
\text { extrapolated indications, and provide data on switching between } \\
\text { reference products and biosimilars }\end{array}$ \\
\hline
\end{tabular}

Republished from Barriers to Oncology Biosimilars Uptake in the United States, Nabhan C et al., The Oncologist , 23 (11), Copyright Wiley 2018 [8]; permission conveyed through Copyright Clearance Center, Inc.

online medical chart review study of the treatment of non-Hodgkin lymphoma (NHL) in five countries found that patients who had received first-line treatment, and had indolent disease and FL, were more likely to be treated with a rituximab biosimilar than with the reference product [57].

RWE can support physicians and patients when making decisions on nonmedical switching, to or from a reference biologic, for reasons relating to treatment cost or availability, rather than as a medical requirement [58,59]. Randomized clinical trials are powered to demonstrate efficacy and are largely limited to assessing known adverse events, whereas real-world populations are more appropriate for identifying previously unreported or rare adverse events [60,61]. Evidence from real-world settings could enhance confidence in the safety of biosimilars; for example, the post-market safety experience of granulocyte-colony stimulating factor biosimilars has demonstrated that real-world use in the USA is consistent with global safety data [62].

RWE can be used to determine potential cost savings for payers [55]. For example, researchers have compared the potential time and cost savings, which may be achieved from a US payer perspective, by using different formulations of the reference product and a rituximab biosimilar in the treatment of patients with NHL [63]. In this time- and cost-simulation analysis in patients with NHL receiving R-CHOP therapy (rituximab plus cyclophosphamide, doxorubicin, vincristine and prednisone), subcutaneous delivery of reference rituximab saved on both time and cost compared with intravenous administration. Moreover, intravenous dosing of a proposed rituximab biosimilar in an R-CHOP regimen provided time and cost savings when compared with subcutaneous administration of the reference product [63]. Further real-world studies are needed to determine the extent of the savings that could be achieved in clinical practice [60].

There is increasing interest from regulatory bodies in the use of RWE to support their decision-making, as highlighted in the "Framework for the FDA's real-world evidence program" [45]. The guidance provides a framework for evaluating the use of real-world data to support approvals in new indications for a drug, and for post-approval study requirements, as set out in the 21 st Century Cures Act [45,64]. The framework also highlights potential gaps in the current sources of real-world data; for example, it recommends that electronic patient health records and medical claims data should be utilized. The FDA recommends that strategies to address these gaps should be explored, including the use of mobile technologies and other tools for collecting PROs [45]. Real-world data can provide support throughout the development of all new drugs by identifying unmet treatment needs, generating hypotheses for clinical research, and providing insights on efficacy and safety for pre-regulatory approval and post-approval outcomes [46]. As such, RWE can be used to support the approval of drugs for expanded indications; for example, palbociclib is now approved to treat men with breast cancer, with its approval supported by real-world data from electronic health records and insurance claims [65].

\section{Relevance of RWE in the era of biosimilars in hematology}

As treatment options for hematologic malignancies increase, real-world data can be accumulated to expand the evidence base for disease management in clinical practice [42]. RWE has the potential to address outcomes in clinical practice, and increase understanding of adverse events, use of resources and economic burden [66-68]. This may facilitate evidence-based clinical decision-making and increase the uptake of biosimilars. Real-world studies have evaluated treatment patterns for novel therapies in patients with chronic lymphocytic leukemia to identify sequencing strategies and reasons for treatment discontinuation [69,70]. As more rituximab biosimilars become available, RWE could provide an understanding of the sequence in which patients should be treated with these 
Table 4. Clinical and real-world studies for biosimilars.

\begin{tabular}{|c|c|c|}
\hline Source & Advantages & Disadvantages \\
\hline Randomized clinical trials & $\begin{array}{l}\text { - Well-designed and controlled; high-quality data are } \\
\text { collected } \\
\text { - Patient baseline data are collected }\end{array}$ & $\begin{array}{l}\text { - May not reflect real-world patients seen by physicians due } \\
\text { to strict inclusion and exclusion criteria } \\
\text { - Limited indications are studied } \\
\text { - Patients are followed up for limited time periods }\end{array}$ \\
\hline Observational studies (prospective) & $\begin{array}{l}\text { - Include different population subgroups (e.g., pediatric, } \\
\text { pregnant and older patients) } \\
\text { - Can be designed to address specific efficacy and safety } \\
\text { questions to build confidence in biosimilars } \\
\text { - Provide data on long-term patient outcomes } \\
\text { - Demonstrate efficacy in extrapolated indications }\end{array}$ & - Issues of selection bias and confounding factors \\
\hline Observational studies (retrospective) & $\begin{array}{l}\text { - Evaluate adherence to treatment with biosimilars } \\
\text { - Evaluate switching between reference products and } \\
\text { biosimilars }\end{array}$ & $\begin{array}{l}\text { - Patient baseline data may not be available } \\
\text { - Issues of recall bias and confounding factors }\end{array}$ \\
\hline $\begin{array}{l}\text { Patient registries and electronic health } \\
\text { records }\end{array}$ & $\begin{array}{l}\text { - May identify rare side effects or trends in adverse events } \\
\text { - More broadly representative of clinical settings and } \\
\text { patient populations }\end{array}$ & $\begin{array}{l}\text { - Patient registries can have high set-up and maintenance } \\
\text { costs }\end{array}$ \\
\hline $\begin{array}{l}\text { Review of insurance claims/pharmacy } \\
\text { records }\end{array}$ & $\begin{array}{l}\text { - Provide information on treatment patterns (comparing } \\
\text { use of reference products with biosimilars) } \\
\text { - Provide data on treatment costs }\end{array}$ & $\begin{array}{l}\text { - Prescribing decisions are not always evidence-driven, and } \\
\text { can be affected by other factors, such as physican preference }\end{array}$ \\
\hline
\end{tabular}

drugs and offer invaluable insights into potential comparisons between rituximab biosimilars. Accumulating realworld data may help to reassure physicians and patients on the effectiveness of rituximab biosimilars in extrapolated indications [71].

Improving biosimilar uptake for the treatment of hematologic malignancies has the potential to reduce healthcare costs and expand patient access [14,17]. Increased competition between biosimilars may further reduce the costs of these drugs. However, there is a lack of consensus on the extent of these savings and, in any event, they are not likely to be as large as those obtained for generic drugs [72,73]. Additionally, biosimilars may improve patient care; for example, by enabling patients to receive treatment at an earlier stage of their disease [74,75].

The FDA's Biosimilars Action Plan recommends the increased use of real-world data to facilitate regulatory decision-making related to biosimilars [76]. RWE could also support safety assessments and the appropriate prescribing of biosimilars; for example, by considering data from the FDA's Adverse Event Reporting System and Sentinel Initiative, and data from insurance companies [76]. Real-world studies that accumulate data from a variety of sources, such as patient registries and insurance claims records, can provide further supportive data on the clinical experience of biosimilars. The results from such studies may help inform physicians, patients, manufacturers and regulatory bodies to guide decisions on the use of biosimilars in the treatment of patients across a range of conditions, including hematologic malignancies [55].

\section{Designing effective real-world studies: challenges \& recommendations Challenges}

As more rituximab biosimilars become available (including in extrapolated indications), there is a need for welldesigned real-world studies to gain broader experience of their use in clinical practice and to gain the trust of the prescribing community [77,78]. However, obtaining reliable RWE for biosimilars with high-quality data can be a challenge. The key advantages and disadvantages of clinical and real-world studies in generating evidence on the use of biosimilars are summarized in Table 4. There are, however, several challenges to consider in the design of these studies, including data quality, biases, confounding factors, cost, patient confidentiality, access to data and governance [48,78]. Furthermore, there is a lack of knowledge and awareness of the systems and processes currently in place to support the collection of real-world data and the methods for analyzing these data [79]. Conducting real-world studies is typically less resource intensive than for randomized clinical trials; however, there is no agreedupon design for an effective study, although checklists to ensure any data are of regulatory-grade quality have been proposed [56]. Pragmatic clinical trials can be conducted by physicians to test interventions in real-world clinical practice settings with a more representative range of patients than those included in randomized clinical trials, as eligibility criteria are not as strict [80]. One advantage of these trials is that they can be used to evaluate how an intervention works in various healthcare settings, such as hospitals, clinics or physician practices. 
Physicians and their patients may have concerns about switching to a biosimilar in the middle of a treatment cycle for cost rather than medical reasons [8]. Therefore, some physicians and pharmacists might need additional sources of evidence on the effects of switching from the reference product to a biosimilar, as regulatory agencies generally do not require switching studies to be conducted for the approval of a biosimilar [81]. Oncologists must decide if and when treatment should be switched to biosimilars, either to or from a reference product or between different biosimilars [82]. Most physicians are unlikely to switch unless financial or other 'toxicities' emerge [83]. While the FDA requires switching studies for approved biosimilars to be designated as interchangeable, it does not require clinical trials in each extrapolated indication [81]. However, a lack of confidence in the efficacy and safety of rituximab biosimilars could lead to lower uptake. This in turn might increase the time required to collect sufficient data to undertake robust real-world studies, particularly if these are retrospective. Furthermore, stakeholders might require RWE that is based on region-specific data and they may not fully accept evidence based on data generated outside their region.

\section{Recommendations}

As rituximab biosimilars have only recently been approved for use in the USA, real-world data on their use in clinical practice are lacking; as such, initial studies should be prospective (e.g., a registry that captures patientlevel data on the use of the biosimilar and reference product). As evidence on the real-world use of rituximab biosimilars accumulates, retrospective studies could be designed to address clinical and economic outcomes. Such studies may help to inform stakeholders and patients that RWE can be used alongside data from clinical trials to broaden the evidence base on the efficacy and safety of rituximab biosimilars [46]. These studies should also include additional information, such as PROs and economic analyses. PROs (e.g., health-related quality of life, and patient preference and satisfaction) could aid differentiation between competing products as more rituximab biosimilars are approved [55,84]. Documentation of PROs can contribute to an improved understanding of the overall efficacy of approved drugs; for example, by recording accurate information on patients' symptom burden [84]. Such studies may enable biosimilar costs to be evaluated in relation to patient outcomes [85]. To ensure that real-world studies are designed to address meaningful questions, it is important to consider the views of all stakeholders, including patients [78]. However, best practices for involving different stakeholders when designing and conducting real-world studies are still being developed [78].

Collaborations are required between organizations that are adept at generating real-world data and groups with expertise in the analysis, interpretation and dissemination of these findings [55]. Biosimilar manufacturers and their collaborators could alleviate some of the concerns that physicians may have about the safety and effectiveness of biosimilars by designing real-world studies that provide supportive evidence for the safety of biosimilars. The American Society of Clinical Oncology’s 'big data' initiative, CancerLinQ ${ }^{\circledR}$, could potentially contribute valuable information on biosimilar use and effectiveness by integrating real-time data for clinical oncology practice and identifying safety concerns in real-world settings [86].

It will be important to identify whether further clinical evidence is required, and to prioritize specific questions regarding the use of biosimilars that can be addressed in real-world studies [55]. Evaluating the long-term use of biosimilars requires not only financial support from relevant stakeholders but also a consensus on the questions that should be addressed; for example, is the primary concern safety or efficacy and should real-world studies compare biosimilars with their reference product or with other rituximab biosimilars. Real-world studies also need to be designed using appropriate methods for data collection in each NHL indication. There is therefore a need to establish a working group to address the specific challenges of collating RWE on biosimilars for the treatment of hematologic malignancies, and to develop a consensus statement to ensure some level of evidence for the quality and comparability of data. Demonstrating the real-world value of rituximab biosimilars to all stakeholders is key to improving patient access and increasing the uptake of these drugs. As such, there are opportunities to design effective real-world studies to provide reliable long-term data on rituximab biosimilars.

\section{Conclusion}

Designing and conducting effective real-world studies for rituximab biosimilars may help to overcome barriers to their adoption by stakeholders. RWE can provide long-term data on the efficacy and safety of rituximab biosimilars in more diverse patient populations, particularly those not studied in clinical trials. This evidence could also support decision-making on non-medical switching, to or from a reference biologic. As randomized clinical trials are often costly to conduct, RWE can provide supportive evidence to help achieve lower-priced biologics and improve patient 
access to these therapies. As such, RWE has the potential to help sustain the treatment of hematologic malignancies with biologics, including biosimilars.

\section{Future perspective}

Treatment options for hematological malignancies are anticipated to expand in the future as more rituximab biosimilars are approved. Stakeholders including patients and physicians will need more information to aid differentiation between biosimilars to support decision-making on the appropriate treatment for each patient. Real-world studies have an important role in providing reliable data on long-term patient outcomes, understanding the sequence in which patients should be treated with these drugs and demonstrating the efficacy of rituximab biosimilars in extrapolated indications. Mobile technologies (such as, wearable electronic devices) are likely to support real-world

\section{Executive summary}

\section{Background}

- Healthcare expenditure for cancer treatment is increasing, partly due to the cost of biologic drugs, creating a challenge for the future sustainability of affordable cancer care.

- As patent portfolios for biologics are nearing end of term, drug companies are developing biosimilars that may provide more affordable treatment options and increase patient access to these important therapies.

- Demonstrating the value of rituximab biosimilars to stakeholders (including patients and healthcare providers) in the real world is key to improving patient access; however, there are currently several barriers to the adoption of rituximab biosimilars.

Regulatory guidance \& rituximab biosimilars

- To gain regulatory approval, biosimilars must be sufficiently similar to the corresponding reference biologic such that they are not expected to show any clinically meaningful differences in efficacy, safety and purity.

- Biosimilar approval is established using a 'totality-of-the-evidence' approach, comprising comparative analytical, preclinical, clinical pharmacokinetic, and efficacy and safety studies in an appropriate patient population.

- Some rituximab biosimilars have been approved in the USA and the European Union through these pathways and there are several other rituximab biosimilars currently in development.

Real-world studies

- Real-world studies can provide insights into different aspects of treatment and patient outcomes to supplement the evidence generated from conventional clinical trials in selected patient populations.

- Real-world data can be collected from a variety of sources including electronic patient health records, claims data, product and disease registries, PROs as well as from emerging data sources, such as social media and industry collaborations.

Relevance of RWE to healthcare stakeholders

- RWE can demonstrate the efficacy and safety of biosimilars in patient populations for whom clinical trial data are not available.

- Evidence on the use of biosimilars from real-world settings could enhance stakeholder confidence in the safety of these drugs.

Relevance of RWE in the era of biosimilars in hematology

- RWE has the potential to address outcomes in clinical practice, and increase understanding of adverse events, use of healthcare resources and the economic burden on healthcare systems.

- As more rituximab biosimilars become available, RWE may help inform physicians, patients, manufacturers and regulatory bodies to guide decisions on the use of these drugs for the treatment of hematologic malignancies.

Designing effective real-world studies: challenges \& recommendations

- Obtaining reliable RWE for biosimilars can be challenging and there are several factors to consider when designing real-world studies, including data quality, biases, confounding factors, cost, patient confidentiality, access to data and governance.

- Real-world data on the use of rituximab biosimilars in clinical practice are lacking so initial studies should be prospective (e.g., registries to capture patient-level data on the use of the biosimilar and reference product).

- Retrospective studies could be designed to address clinical and economic outcomes, and acquisition of additional information such as PROs to aid differentiation between different biosimilars.

- Collaborations are required between organizations that are adept at generating real-world data and groups with expertise in the analysis, interpretation and dissemination of these findings.

Conclusion

- Providing real-world data on the efficacy and safety of rituximab biosimilars may help to overcome barriers to their adoption by stakeholders.

- RWE can provide supportive evidence to help achieve lower-priced biologics, improve patient access to these therapies and help sustain the treatment of hematologic malignancies with biologics, including biosimilars. 
studies to collect data on PROs, such as health-related quality of life, and patient preference and satisfaction. Reassuring stakeholders on the efficacy and safety of rituximab biosimilars by accumulating reliable evidence through well-designed real-world studies can potentially help increase the uptake of rituximab biosimilars and, in turn, reduce healthcare costs for the treatment of hematologic malignancies.

Supplementary data

A Plain Language Summary is available for this paper. To view and download the Plain Language Summary, please visit the journal website at: www.futuremedicine.com/doi/full/10.2217/fon-2020-0131

\section{Financial \& competing interests disclosure}

This review was sponsored by Pfizer. P Nava-Parada and A Shelbaya are full-time employees of and declare stock holdings and/or stock options from Pfizer. C Nabhan was an employee of Aptitude Health, which collaborates with Pfizer on biosimilar projects. The authors have no other relevant affiliations or financial involvement with any organization or entity with a financial interest in or financial conflict with the subject matter or materials discussed in the manuscript apart from those disclosed.

Medical writing support was provided by J Oliver of Engage Medical Affairs and was funded by Pfizer.

\section{Open access}

This work is licensed under the Attribution-NonCommercial-NoDerivatives 4.0 Unported License. To view a copy of this license, visit http://creativecommons.org/licenses/by-nc-nd/4.0/

\section{References}

Papers of special note have been highlighted as: $\bullet$ of interest; $\bullet \bullet$ of considerable interest

1. Patel KB, Arantes LH Jr, Tang WY, Fung S. The role of biosimilars in value-based oncology care. Cancer Manag. Res. 10, 4591-4602 (2018).

2. Jacobs I, Ewesuedo R, Lula S, Zacharchuk C. Biosimilars for the treatment of cancer: a systematic review of published evidence. BioDrugs 31(1), 1-36 (2017).

3. Cornes P. The economic pressures for biosimilar drug use in cancer medicine. Target. Oncol. 7(Suppl. 1), S57-S67 (2012).

4. Salles G, Barrett M, Foa R et al. Rituximab in B-cell hematologic malignancies: a review of 20 years of clinical experience. Adv. Ther. 34(10), 2232-2273 (2017).

5. EMA. European public assessment report for MabThera. www.ema.europa.eu/en/medicines/human/EPAR/mabthera

6. Biogen and Genentech USA Inc. Rituxan ${ }^{\circledR}$. Prescribing information (1997). www.gene.com/download/pdf/rituxan_prescribing.pdf

7. Baer WH II, Maini A, Jacobs I. Barriers to the access and use of rituximab in patients with non-Hodgkin's lymphoma and chronic lymphocytic leukemia: a physician survey. Pharmaceuticals 7(5), 530-544 (2014).

8. Nabhan C, Valley A, Feinberg BA. Barriers to oncology biosimilars uptake in the United States. Oncologist 23(11), 1261-1265 (2018).

- Outlines the economic, policy and stakeholder perception barriers that have an impact on the uptake of oncology biosimilars in the USA.

9. US FDA. Scientific considerations in demonstrating biosimilarity to a reference product: guidance for industry (2015). www.fda.gov/media/82647/download

10. EMA. Guideline on similar biological medicinal products (2014). www.ema.europa.eu/docs/en_GB/document_library/Scientific_guideline/2014/10/WC500176768.pdf

11. Falit BP, Singh SC, Brennan TA. Biosimilar competition in the United States: statutory incentives, payers, and pharmacy benefit managers. Health Aff. 34(2), 294-301 (2015).

12. Subramanian J, Cavenagh J, Desai B, Jacobs I. Rituximab in the treatment of follicular lymphoma: the future of biosimilars in the evolving therapeutic landscape. Cancer Manag. Res. 9, 131-140 (2017).

13. Qureshi ZP, Nagai S, Bennett CL. Biosimilar filgrastim use in the United States vs the European Union and Japan - why does it lag behind and what can be done? JAMA Oncol. 5(3), 297-298 (2019).

14. Boccia R, Jacobs I, Popovian R, de Lima Lopes G Jr. Can biosimilars help achieve the goals of US health care reform? Cancer Manag. Res. 9, 197-205 (2017).

15. US FDA. Biosimilar development, review, and approval (2017). www.fda.gov/drugs/developmentapprovalprocess/howdrugsaredevelope dandapproved/approvalapplications/therapeuticbiologicapplications/biosimilars/ucm $580429 . \mathrm{htm}$

16. Alten R, Cronstein BN. Clinical trial development for biosimilars. Semin. Arthritis Rheum. 44(Suppl. 6), S2-S8 (2015).

17. Nabhan C, Parsad S, Mato AR, Feinberg BA. Biosimilars in oncology in the United States: a review. JAMA Oncol. 4(2), 241-247 (2018). 
18. WHO. Guidelines on evaluation of similar biotherapeutic products (SBPs) (2009). www.who.int/biologicals/areas/biological_therapeutics/BIOTHERAPEUTICS_FOR_WEB_22APRIL2010.pdf

19. Garcia R, Araujo DV. The regulation of biosimilars in Latin America. Curr. Rheumatol. Rep. 18(3), 16 (2016).

20. Tsai WC. Update on biosimilars in Asia. Curr. Rheumatol. Rep. 19(8), 47 (2017).

21. Health Canada. Guidance Document. Information and submission requirements for biosimilar biologic brugs (2010). www.canada.ca/ content/dam/hc-sc/migration/hc-sc/dhp-mps/alt_formats/pdf/brgtherap/applic-demande/guides/seb-pbu/seb-pbu-2016-eng.pdf

22. Kabir ER, Moreino SS, Sharif Siam MK. The breakthrough of biosimilars: a twist in the narrative of biological therapy. Biomolecules 9(9), 410 (2019).

23. Yoo DH, Suh $\mathrm{CH}$, Shim SC et al. A multicentre randomised controlled trial to compare the pharmacokinetics, efficacy and safety of CT-P10 and innovator rituximab in patients with rheumatoid arthritis. Ann. Rheum. Dis. 76(3), 566-570 (2017).

24. Yoo DH, Suh CH, Shim SC et al. Efficacy, safety and pharmacokinetics of up to two courses of the rituximab biosimilar CT-P10 versus innovator rituximab in patients with rheumatoid arthritis: results up to week 72 of a phase I randomized controlled trial. BioDrugs 31(4), 357-367 (2017).

25. Park W, Bozic-Majstorovic L, Milakovic D et al. Comparison of biosimilar CT-P10 and innovator rituximab in patients with rheumatoid arthritis: a randomized controlled Phase 3 trial. MAbs 10(6), 934-943 (2018).

26. Kim WS, Buske C, Ogura M et al. Efficacy, pharmacokinetics, and safety of the biosimilar CT-P10 compared with rituximab in patients with previously untreated advanced-stage follicular lymphoma: a randomised, double-blind, parallel-group, non-inferiority phase 3 trial. Lancet Haematol. 4(8), e362-e373 (2017).

27. Ogura M, Sancho JM, Cho SG et al. Efficacy, pharmacokinetics, and safety of the biosimilar CT-P10 in comparison with rituximab in patients with previously untreated low-tumour-burden follicular lymphoma: a randomised, double-blind, parallel-group, phase 3 trial. Lancet Haematol. 5(11), e543-e553 (2018).

28. Celltrion Inc. Truxima. Summary of product characteristics (2017). www.ema.europa.eu/en/documents/product-information/truxima-epar-product-information_en.pdf

29. Celltrion Inc. Ritemvia. Summary of product characteristics (2017). www.ema.europa.eu/en/documents/product-information/ritemvia-epar-product-information_en.pdf

30. Celltrion Inc. Blitzima. Summary of product characteristics (2017). www.ema.europa.eu/en/documents/product-information/blitzima-epar-product-information_en.pdf

31. Celltrion Inc. Truxima ${ }^{\circledR}$ (rituximab-abbs) prescribing information (2018). www.accessdata.fda.gov/drugsatfda_docs/label/2018/761088s000lbl.pdf

32. Smolen J, Scheinberg M, Tony H-P, Zhu P, Shisha T. FRI0222 pharmacokinetics, pharmacodynamics, safety and efficacy of proposed rituximab biosimilar (GP2013) vs. EU-approved rituximab (RTX) in patients with rheumatoid arthritis: results from a randomized controlled trial (GP13-201) over 52 weeks. Ann. Rheum. Dis. 75(Suppl. 2), 512-513 (2016).

33. Jurczak W, Moreira I, Kanakasetty GB et al. Rituximab biosimilar and reference rituximab in patients with previously untreated advanced follicular lymphoma (ASSIST-FL): primary results from a confirmatory Phase III, double-blind, randomised, controlled study. Lancet Haematol. 4(8), e350-e361 (2017).

34. Sandoz. Rixathon. Summary of product characteristics (2017). www.ema.europa.eu/en/documents/product-information/rixathon-epar-product-information_en.pdf

35. Sandoz. Riximyo. Summary of product characteristics (2017). www.ema.europa.eu/en/documents/product-information/riximyo-epar-product-information_en.pdf

36. Cohen S, Emery P, Greenwald M et al. A Phase I pharmacokinetics trial comparing PF-05280586 (a potential biosimilar) and rituximab in patients with active rheumatoid arthritis. Br. J. Clin. Pharmacol. 82(1), 129-138 (2016).

37. Cohen SB, Burgos-Vargas R, Emery P, Jin B, Cronenberger C, Vazquez-Abad MD. Extension study of PF-05280586, a potential rituximab biosimilar, versus rituximab in subjects with active rheumatoid arthritis. Arthritis Care Res. (Hoboken). 70(11), 1598-1606 (2018).

38. Sharman J, Liberati AM, Santucci Silva R et al. A randomized, double-blind efficacy and safety study of PF-05280586 (a potential rituximab biosimilar) compared with rituximab reference product (MabThera ${ }^{\circledR}$ ) in subjects with previously untreated CD20-positive, low tumor burden follicular lymphoma (LTB-FL). Blood 132(Suppl. 1), 394 (2018).

39. Pfizer Inc. Ruxience ${ }^{\top M}$ (rituximab-pvvr) prescribing information (2019). www.accessdata.fda.gov/drugsatfda_docs/label/2019/761103s000lbl.pdf

40. EMA. Summary of Product Characteristics for Ruxience (2020). www.ema.europa.eu/en/documents/product-information/ruxience-epar-product-information_en.pdf

41. Amgen. Study to assess if ABP798 is safe \& effective in treating non Hodgkin lymphoma compared to rituximab (JASMINE). www.amgentrials.com/amgen/trialsummary.aspx?studyid=20130109

42. GaBi online. Biosimilars of rituximab (2015). www.gabionline.net/Biosimilars/General/Biosimilars-of-rituximab 
43. Mabion. https://www.mabion.eu/en/blog/mabion-s-completes-marketing-authorisation-application-flagship-drug-mabioncd20-euro pean-medicines-agency-ema/

44. GaBi online. More positive phase III results for rituximab biosimilar ABP 798 (2019). http://gabionline.net/Biosimilars/Research/More-positive-phase-III-results-for-rituximab-biosimilar-ABP-798

45. US FDA. Framework for FDA's real-world evidence program (2018). www.fda.gov/media/120060/download

46. The Network for Excellence in Health Innovation. Real world evidence: a new era for health care innovation (2015). www.nehi.net/writable/publication_files/file/rwe_issue_brief_final.pdf

47. Nabhan C, Klink A, Prasad V. Real-world evidence - what does it really mean? JAMA Oncol. 5(6), 781-783 (2019).

48. IQVIA and London School of Economics. Real-world evidence in oncology towards innovative and affordable patient care (2018). www.iqvia.com/locations/uk-and-ireland/library/white-papers/real-world-evidence-in-oncology

49. Webster J, Smith BD. The case for real-world evidence in the future of clinical research on chronic myeloid leukemia. Clin. Ther. 41(2), 336-349 (2019).

50. Matasar MJ, Qiu A, Shapouri S et al. Real-world assessment of practice efficiency with the introduction of subcutaneous rituximab. Hematol. Oncol. 37(S2), 540 (2019).

51. Sherman RE, Anderson SA, Dal Pan GJ et al. Real-world evidence - what is it and what can it tell us? N. Engl. J. Med. 375(23), 2293-2297 (2016).

52. National Institute for Health and Care Excellence. Biosimilar medicines (2016). www.nice.org.uk/advice/ktt15/resources/biosimilar-medicines-58757954414533

53. Reinisch W, Smolen J. Biosimilar safety factors in clinical practice. Semin. Arthritis Rheum. 44(Suppl. 6), S9-S15 (2015).

54. Cohen H, Beydoun D, Chien D et al. Awareness, knowledge, and perceptions of biosimilars among specialty physicians. Adv. Ther. 33(12), 2160-2172 (2017).

55. Ronnebaum S, Atzinger C. Enhancing biosimilar adoption with real-world evidence (2018). www.ispor.org/docs/default-source/publicat ions/value-outcomes-spotlight/july-august-2018/ispor-vos-august-2018-heor-article-enhancing-biosimilars.pdf?sfvrsn=8f27535f_2

56. Miksad RA, Abernethy AP. Harnessing the power of real-world evidence (RWE): a checklist to ensure regulatory-grade data quality. Clin. Pharmacol. Ther. 103(2), 202-205 (2018).

- Presents a proposed checklist to facilitate the collection of regulatory-grade real-world data.

57. Franceschetti A, Caldeira R. Treatment approach for non-Hodgkin lymphoma patients since first biosimilars of rituximab approved in EU5. J. Clin. Oncol. 36(Suppl. 15), 112 (2018).

58. Teeple A, Ginsburg S, Howard L et al. Patient attitudes about non-medical switching to biosimilars: results from an online patient survey in the United States. Curr. Med. Res. Opin. 34(4), 603-609 (2019).

59. McKinnon RA, Cook M, Liauw W et al. Biosimilarity and interchangeability: principles and evidence: a systematic review. BioDrugs 32(1), 27-52 (2018).

60. Suvarna V. Phase IV of drug development. Perspect. Clin. Res. 1(2), 57-60 (2010).

61. Berlin JA, Glasser SC, Ellenberg SS. Adverse event detection in drug development: recommendations and obligations beyond phase 3. Am. J. Public Health 98(8), 1366-1371 (2008).

62. Abboud CN, Lang N, Fung H et al. Real-world safety experience of tevagrastim/ratiograstim/biograstim and tbo-filgrastim, short-acting recombinant human granulocyte colony-stimulating factors. Support. Care Cancer 27(7), 2569-2577 (2018).

63. McBride A, Balu S, Campbell K, MacDonald K, Abraham I. Subcutaneous versus intravenous rituximab in non-Hodgkin lymphoma treated with R-CHOP: economic modeling for the US. Blood 132(Suppl. 1), 4776 (2018).

64. US FDA. 21st Century Cures Act. Public Law. 114-255 (2016). www.congress.gov/114/plaws/publ255/PLAW-114publ255.pdf

65. Wedam S, Fashoyin-Aje L, Bloomquist E et al. FDA approval summary: palbociclib for male patients with metastatic breast cancer. Clin. Cancer Res. 26(6), 1208-1212 (2020).

66. Goyal RK, Nagar SP, Kabadi SM, Kaye JA, Seal B, Mato AR. Adverse events, resource use, and economic burden associated with mantle cell lymphoma: a real-world assessment of privately insured patients in the United States. Leuk. Lymphoma 60(4), 955-963 (2019).

67. Scavone C, Sessa M, Clementi E et al. Real world data on the utilization pattern and safety profile of infliximab originator versus biosimilars in Italy: a multiregional study. BioDrugs 32(6), 607-617 (2018).

68. Leonard E, Wascovich M, Oskouei S, Gurz P, Carpenter D. Factors affecting health care provider knowledge and acceptance of biosimilar medicines: a systematic review. J. Manag. Care Spec. Pharm. 25(1), 102-112 (2019).

- Systematic review evaluating healthcare provider knowledge, perceptions and prescribing patterns of biosimilars in the USA and Europe.

69. Mato AR, Hill BT, Lamanna $\mathrm{N}$ et al. Optimal sequencing of ibrutinib, idelalisib, and venetoclax in chronic lymphocytic leukemia: results from a multicenter study of 683 patients. Ann. Oncol. 28(5), 1050-1056 (2017). 
70. Mato AR, Samp JC, Gauthier G, Terasawa E, Brander DM. Drivers of treatment patterns in patients with chronic lymphocytic leukemia stopping ibrutinib or idelalisib therapies. Cancer Biol. Ther. 1977), 636-643 (2018).

71. Ogura M, Coiffier B, Kwon HC, Yoon SW. Scientific rationale for extrapolation of biosimilar data across cancer indications: case study of CT-P10. Future Oncol. 13(15s), 45-53 (2017).

72. Manolis CH, Rajasenan K, Harwin W, McClelland S, Lopes M, Farnum C. Biosimilars: opportunities to promote optimization through payer and provider collaboration. J. Manag. Care Spec. Pharm. 22(Suppl. 9), S3-S9 (2016).

73. Mulcahy AW, Predmore Z, Mattke S. The cost savings potential of biosimilar drugs in the United States (2014). www.rand.org/content/dam/rand/pubs/perspectives/PE100/PE127/RAND_PE127.pdf

74. Gascon P, Tesch H, Verpoort K et al. Clinical experience with Zarzio ${ }^{\circledR}$ in Europe: what have we learned? Support. Care Cancer 21(10), 2925-2932 (2013).

75. Henry D, Taylor C. Pharmacoeconomics of cancer therapies: considerations with the introduction of biosimilars. Semin. Oncol. 41(Suppl. 3), S13-S20 (2014).

76. US Food and Drug Administration. Biosimilars action plan: balancing innovation and competition (2018). www.fda.gov/media/114574/download

77. Greenwald M, Tesser J, Sewell KL. Biosimilars have arrived: rituximab. Arthritis. 2018, 3762864 (2018).

78. Berger ML, Sox H, Willke RJ et al. Good practices for real-world data studies of treatment and/or comparative effectiveness: recommendations from the Joint ISPOR-ISPE Special Task Force on real-world evidence in health care decision making. Value Health. 20(8), 1003-1008 (2017).

-. Presents recommendations from the International Society for Pharmacoeconomics and Outcomes Research and the International Society for Pharmacoepidemiology Special Task Force for good practices for real-world studies of treatment effectiveness.

79. The Forum on Drug Discovery, Development, and Translation of the National Academies of Sciences, Engineering, and Medicine. Examining the impact of real-world evidence (RWE) on medical product development. (2019). http://nationalacademies.org/hmd/Activities/Research/DrugForum/2018-July-17/rwe-proceedings-of-a-workshop-series.aspx

80. Ford I, Norrie J. Pragmatic trials. N. Engl. J. Med. 375(5), 454-463 (2016).

81. Declerck P, Bakalos G, Zintzaras E, Barton B, Schreitmuller T. Monoclonal antibody biosimilars in oncology: critical appraisal of available data on switching. Clin. Ther. 40(5), 798-809 e2 (2018).

82. Rugo HS, Linton KM, Cervi P, Rosenberg JA, Jacobs I. A clinician's guide to biosimilars in oncology. Cancer Treat. Rev. 46, 73-79 (2016).

83. Wehrwein P. A conversation with Gary Lyman, MD: biosimilars and the search for the cure to cancer treatment's financial toxicity. Manag. Care 28(1), 12-15 (2019).

84. Efficace F, Gaidano G, Lo-Coco F. Patient-reported outcomes in hematology: is it time to focus more on them in clinical trials and hematology practice? Blood 130(7), 859-866 (2017).

-. Outlines the value of a systematic and rigorous implementation of assessing patient-reported outcomes in hematology treatment and provides examples of how real-world data have contributed to an improved understanding of the value of new therapies.

85. Smeeding J, Malone DC, Ramchandani M, Stolshek B, Green L, Schneider P. Biosimilars: considerations for payers. Pharmacol. Ther. 44(2), 54-63 (2019).

86. Lyman GH, Balaban E, Diaz M et al. American Society of Clinical Oncology statement: biosimilars in oncology. J. Clin. Oncol. 36(12), 1260-1265 (2018). 
